\title{
Multivectorial paleointensity determination from the Cordova Gabbro, southern Ontario
}

\author{
Yongjae Yu*, David J. Dunlop \\ Geophysics, Department of Physics, University of Toronto, Toronto, ON, Canada
}

Received 14 May 2002; received in revised form 5 July 2002; accepted 5 July 2002

\begin{abstract}
We report geomagnetic field intensities for the $\mathrm{A}(\sim 1000 \mathrm{Ma})$ and $\mathrm{B}(\sim 850 \mathrm{Ma})$ natural remanent magnetizations of the Cordova Gabbro of southern Ontario. We interpret A and B to be secondary thermal overprints produced during regional uplift and cooling following the Grenvillian Orogeny. Multivectorial A+B paleointensity data were analyzed using pairs of Arai diagrams for the separated A and B vectors. From 18 reliable A results and 15 reliable B results, we find paleofield values of $18.1 \pm 2.1 \mu \mathrm{T}$ and $7.1 \pm 1.5 \mu \mathrm{T}$, respectively. The corresponding virtual axial dipole moments (VADMs) are (3.12 \pm 0.36$)$ and $(1.82 \pm 0.38) \times 10^{22} \mathrm{~A} \mathrm{~m}^{2}$, about $70 \%$ and $40 \%$ of the average Phanerozoic dipole moment based on data from 0.3-300 Ma. The Cordova data and other Precambrian paleointensities are generally within a range of approximately $0.5-1.5$ times the Phanerozoic mean VADM. Three sets of paleofield values as a function of paleolatitude, including the Cordova data, support a dipole configuration for the Earth's field in 25$150 \mathrm{Ma}$ time windows around $2700 \mathrm{Ma}, 1100 \mathrm{Ma}$, and $850 \mathrm{Ma}$.
\end{abstract}

(C) 2002 Elsevier Science B.V. All rights reserved.

Keywords: Cordova Gabbro; remagnetization; natural remanent magnetization; Precambrian; paleointensity; VADM

\section{Introduction}

The intensity variation of the Earth's magnetic field during Precambrian time provides important information about the early evolution of the geodynamo and the Earth's core. Only 17 Thelliertype [1] paleointensity results have been published for the Precambrian. With the exception of two

\footnotetext{
* Corresponding author. Tel.: +1-905-828-3968; Fax: +1-905-828-5425.

E-mail address: yjyu@physics.utoronto.ca (Y. Yu).
}

very high values, the Precambrian studies have given dipole moments that are similar to Phanerozoic values, with a variation of about a factor two around the long-term mean [2].

In this paper, we report Thellier paleointensity determinations for 18 specimens of the Cordova Gabbro of southern Ontario, which has multivectorial natural remanent magnetization (NRM). As well as determining paleofield values for the A NRM, which has high unblocking temperatures $\left(T_{\mathrm{UB}} \mathrm{S}\right)$ and dates from $\sim 1000 \mathrm{Ma}$, we were able to determine paleointensities from the $\sim 850 \mathrm{Ma}$ medium- $T_{\mathrm{UB}} \mathrm{B}$ NRM in 15 specimens. To our knowledge, this is the first published study of multivectorial paleointensity determination. 


\section{Geology and paleomagnetic background}

The Cordova Gabbro (CO in Fig. 1a) is located in the southernmost part of the late Precambrian Grenville Province of Ontario, in the Belmont Domain of the Hastings Lowlands or Elsevir Terrane [3]. A schematic geological map of the Cordova Gabbro appears in Fig. 1b. Surrounding volcanic rocks, with $\mathrm{U} / \mathrm{Pb}$ ages of $1310 \pm 15 \mathrm{Ma}$ [4], were intruded by the Cordova around 1242 $\mathrm{Ma}(\mathrm{U} / \mathrm{Pb}$ on zircon [5]).

An early paleomagnetic study in the adjacent Hastings-Haliburton Highlands discovered multivectorial NRMs in the Haliburton intrusions (HB in Fig. 1a) of the Bancroft Terrane [6]. The older A NRM, with high $T_{\mathrm{UB}} \mathrm{S}$, has a paleomagnetic pole, $\mathrm{HB}_{\mathrm{A}}$, near Australia (Fig. 2). The B NRM, with intermediate $T_{\mathrm{UB}} \mathrm{s}$, has a paleopole $\mathrm{HB}_{\mathrm{B}}$ in the equatorial Pacific. A and B separated cleanly in thermal demagnetization with minimal overlap of their $T_{\mathrm{UB}}$ ranges, implying that $\mathrm{B}$ is a thermal overprint of $\mathrm{A}$. That is, B is a partial thermoremanent magnetization (TRM).

McWilliams and Dunlop [7] suggested that the $\mathrm{HB}_{\mathrm{A}}$ and $\mathrm{HB}_{\mathrm{B}}$ poles together with other paleopoles from the Grenville Province belong to a post-orogenic Grenville Track that is younger than the 1150-1050 Ma Keweenawan Track. They proposed a counterclockwise loop that youngs from the equatorial Pacific to Australia. Most subsequent authors have favored instead a clockwise loop which youngs from Australia to the equator because it incorporates $\mathrm{A}$ and $\mathrm{B}$ poles in a natural time sequence (see, for example, [8]).

However, the counterclockwise loop has recently returned to favor [9], both because it provides a shorter link with the earlier Keweenawan Track and because it accommodates plate tectonic interpretations based on matching apparent polar paths from other continents. On the other hand, (a)

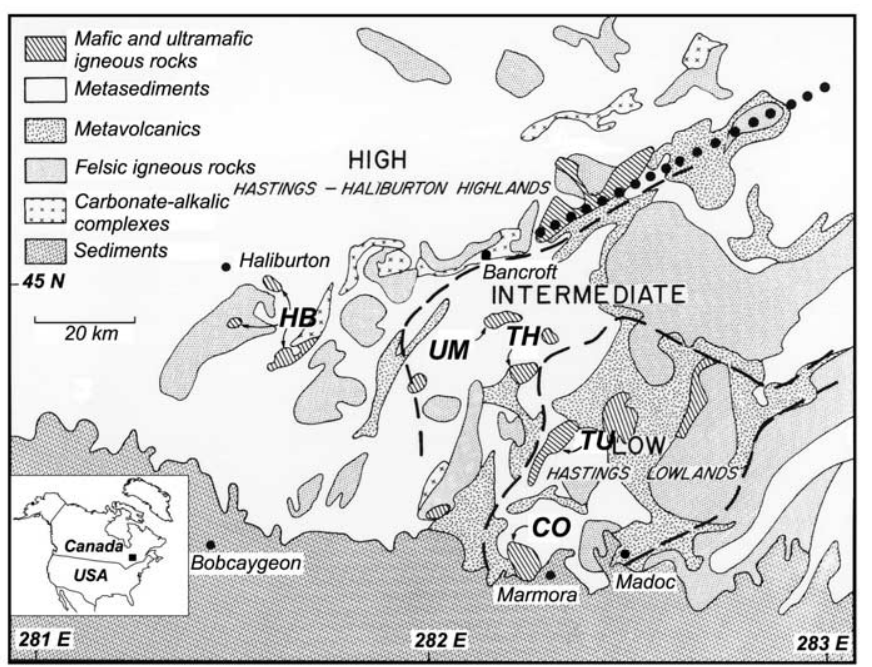

(b)

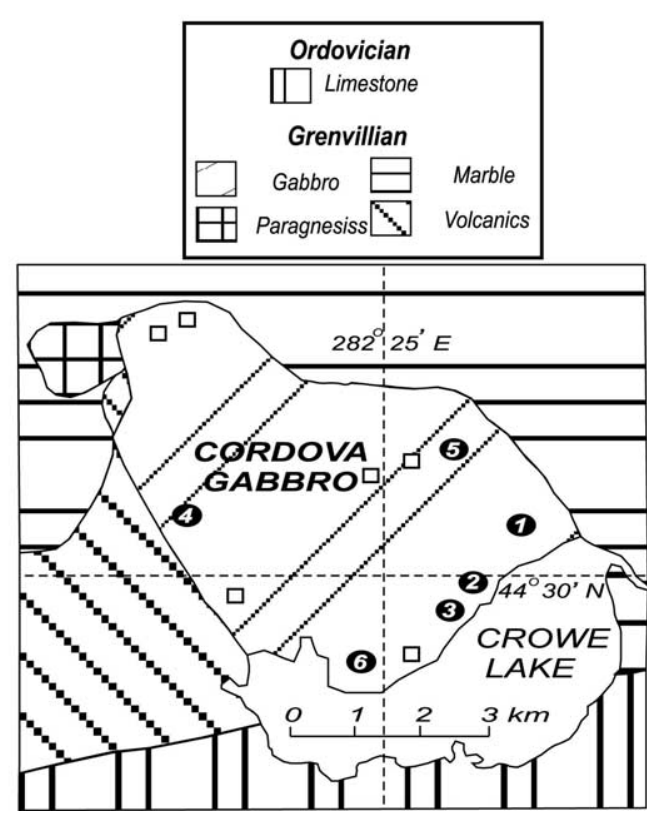

Fig. 1. (a) Metamorphic zonations in part of the Central Metasedimentary Belt, Grenville Province, southern Ontario. The lowand intermediate-grade zones fall within the Elsevir terrane [3]; the high-grade zone to the northwest is the Bancroft terrane. The Cordova and Tudor Gabbros are designated by CO and TU. (b) A simplified geological map showing the sites sampled in this study. Circles and squares denote sites that yielded at least one accepted paleointensity and no accepted paleointensities, respectively. 
this choice leaves an awkward link from what are then interpreted to be the youngest A poles (e.g. $\mathrm{HB}_{\mathrm{A}}$ ), 30-35 $5^{\circ}$ south of the equator, to still younger $\mathrm{B}$ poles from $\mathrm{CO}, \mathrm{HB}$ and the Thanet Gabbro $(\mathrm{TH})$ of the Elsevir Terrane [10], which lie 20-25 north of the equator. The A to B link is necessitated by the observation that $\mathrm{B}$ is a thermal overprint of $\mathrm{A}$, on the basis of adjacent but non-overlapping $\mathrm{A}$ and $\mathrm{B}$ blocking temperature ranges, a defining property of partial TRMs (pTRMs).

\section{3. ${ }^{40} \mathrm{Ar} /{ }^{39} \mathrm{Ar}$ geochronology}

Absolute time calibration of $\mathrm{A}$ and $\mathrm{B}$ paleopoles is based on matching the characteristic A and $\mathrm{B} T_{\mathrm{UB}} \mathrm{S}$ to temperatures and times of Ar diffusion determined for hornblendes, micas and feldspars from the same rocks, the science of ${ }^{40} \mathrm{Ar} /{ }^{39} \mathrm{Ar}$ thermochronometry [11-16]. In this way, ages of $\sim 980 \mathrm{Ma}$ and $\sim 820 \mathrm{Ma}$ were inferred for $\mathrm{HB}_{\mathrm{A}}$ and $\mathrm{HB}_{\mathrm{B}}$, respectively [11], and 945-980 Ma ages were determined [12] for the A poles $\mathrm{W}_{\mathrm{W}}$ and $\mathrm{W}_{\mathrm{Z}}$ of the Whitestone Diorite (northwest of the map area of Fig. 1a), which fall at $15-20^{\circ} \mathrm{S}$, intermediate between $\mathrm{HB}_{\mathrm{A}}$ and $\mathrm{HB}_{\mathrm{B}}$. The Cordova Gabbro A pole, $\mathrm{CO}_{\mathrm{A}}$, of Dunlop and Stirling [17] and the present study, is an intermediate-latitude $\mathrm{A}$ pole like $\mathrm{W}_{\mathrm{W}}$, falling at $10^{\circ} \mathrm{S}$, while the Cordova $\mathrm{B}$ pole, $\mathrm{CO}_{\mathrm{B}}$, falls at $25^{\circ} \mathrm{N}$, just south of $\mathrm{HB}_{\mathrm{B}}$ (Fig. 2). If the Cordova $A$ and B NRMs are both pTRMs, as we argue below, their ages, by comparison with the timecalibrated clockwise Grenville Track, would be $\sim 930 \mathrm{Ma}$ and $\sim 820 \mathrm{Ma}$, respectively.

On the other hand, more recent ${ }^{40} \mathrm{Ar} /{ }^{39} \mathrm{Ar}$ studies of the Central Metasedimentary Belt (CMB), of which the Bancroft and Elsevir Terranes form the western section, have revealed a variety of post-orogenic uplift thermal histories for different components of the CMB $[14,15]$. More deeply buried and highly metamorphosed terranes like the Bancroft reached their present erosional level at the surface later than originally shallow terranes, specifically the Elsevir. The time offsets in the cooling curves amount to as much as 100-150 Ma ([13]; [14], figures 6-8; [15], figures 6 and 7).

The predominant ${ }^{40} \mathrm{Ar} /{ }^{39} \mathrm{Ar}$ hornblende and phlogopite ages in the central Elsevir are 1000$1020 \mathrm{Ma}[14,15]$. These seem more appropriate for the time of acquisition of the Cordova Gabbro A NRM than older hornblende and biotite ${ }^{40} \mathrm{Ar} /{ }^{39} \mathrm{Ar}$ ages of $1150-1050 \mathrm{Ma}$ [18], which seem to refer to the time of intrusion and preuplift metamorphism. The $\mathrm{CO}_{\mathrm{A}}$ pole does not fall on or near the 1150-1050 Ma Keweenawan Track, but it does fall in the central part of the Grenville Track, which in the interpretation of [9] of poles younging from north to south would place it in the age interval 1050-980 Ma. We therefore tentatively assign an age of $\sim 1000$ $\mathrm{Ma}$ to the Cordova Gabbro A magnetization, based both on pole position and regional ${ }^{40} \mathrm{Ar} /$ ${ }^{39} \mathrm{Ar}$ dates.

The age of thermal overprinting for the Cordova $\mathrm{B}$ is estimated in a similar way. Its typical laboratory $T_{\mathrm{UB}}$ range is $300-500^{\circ} \mathrm{C}$ (next section), roughly matching Ar closure temperatures of muscovite, whose cooling ages in the eastern Elsevir are 890-900 Ma [14]. The position of pole $\mathrm{CO}_{\mathrm{B}}$ on either version of the Grenville Loop implies that it is slightly older than the $820 \mathrm{Ma} \mathrm{HB}_{\mathrm{B}}$. We therefore tentatively take the age of the Cordova $\mathrm{B}$ magnetization to be $\sim 850 \mathrm{Ma}$.

\section{Nature of the Cordova A and B NRMs}

Unlike the nearby Tudor Gabbro (TU in Fig. 1a; intrusion age $1240 \mathrm{Ma}$ [19]), none of the primary TRM of the Cordova Gabbro survived subsequent burial and heating in the Grenvillian orogeny. This conclusion is based on both ${ }^{40} \mathrm{Ar} /$ ${ }^{39} \mathrm{Ar}$ thermochronometry and paleomagnetism. TU and $\mathrm{CO}$ lie in the low-metamorphic-grade central Elsevir (Fig. 1a), where silicate geothermometers indicate reheating to $500-550^{\circ} \mathrm{C}([20]$, figure 6), in agreement with calcite-dolomite and calcite-graphite thermometry on marbles in contact with the Tudor Gabbro [21,22]. However, an ${ }^{40} \mathrm{Ar} /{ }^{39} \mathrm{Ar}$ hornblende age (Ar closure temperature of $\sim 500^{\circ} \mathrm{C}$ ), from Madoc (just east of $\mathrm{CO}$ ) is $1006 \mathrm{Ma}$ and has been reset ([14], figure 3). Our interpretation is that the Tudor Gabbro was never reheated above $500^{\circ} \mathrm{C}[21,22]$ and has preserved its primary TRM [2] whereas the Cordova was 

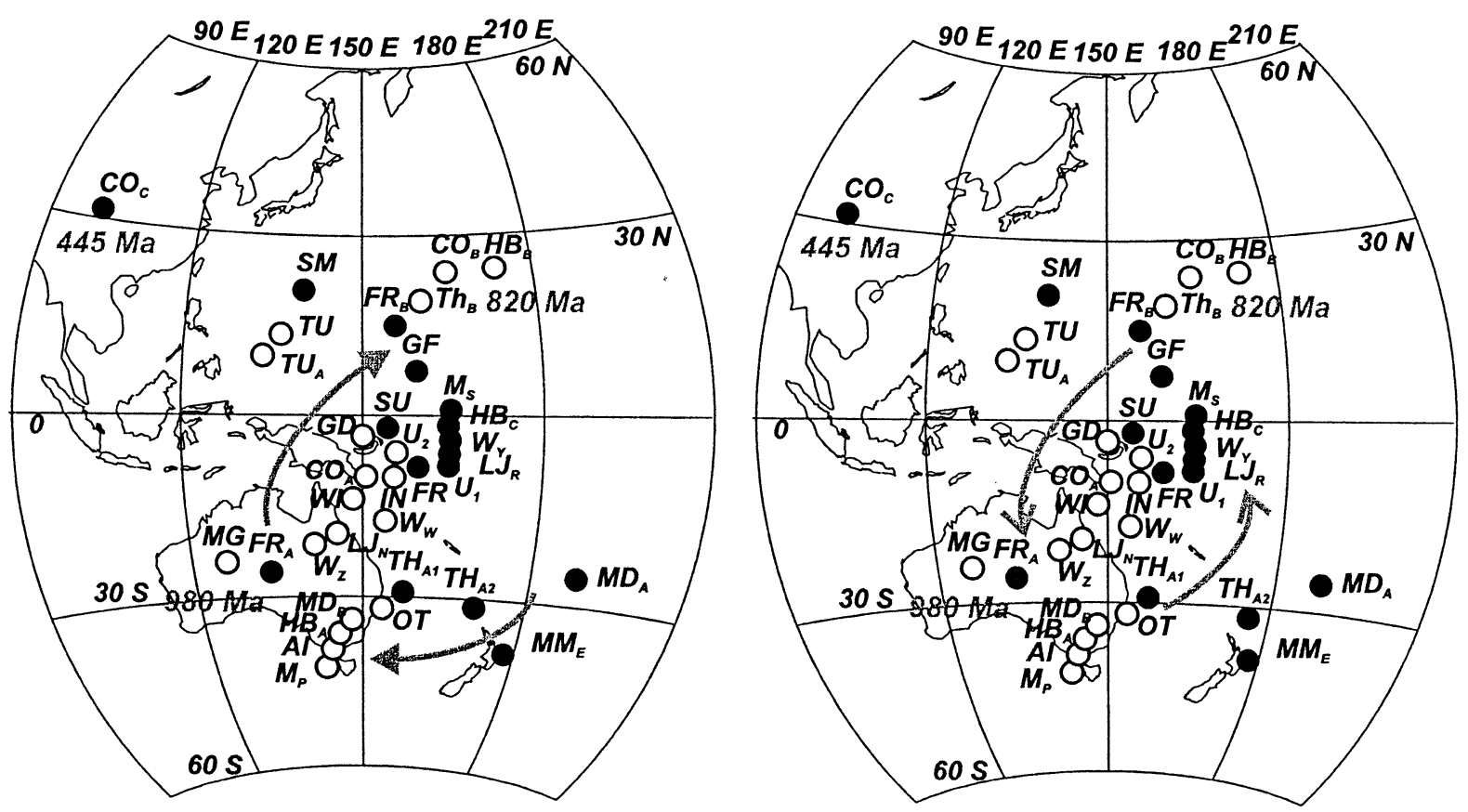

Fig. 2. Compilation of Grenvillian paleopoles after [17], where the individual poles are listed. Open, half-open, and solid symbols denote reversed, mixed, and normal polarity. Both clockwise and counterclockwise versions of the Grenville Loop are shown (see text).

reheated above $500^{\circ} \mathrm{C}$ and later, around $1000 \mathrm{Ma}$, passed through $500^{\circ} \mathrm{C}$ during post-metamorphic uplift and cooling.

The paleomagnetic data for TU and $\mathrm{CO}$ support this conclusion. TU has a high- $T_{\mathrm{UB}} \mathrm{NRM}$ that is unique among Grenvillian data in having a paleopole that falls well off the Grenville Track (Fig. 2). The $\mathrm{CO}_{\mathrm{A}}$ and $\mathrm{CO}_{\mathrm{B}}$ poles, on the other hand, fall squarely on the Grenville Track among large groups of post-metamorphic A and B poles from geographically widely separated formations. $\mathrm{CO}_{\mathrm{A}}$ and $\mathrm{CO}_{\mathrm{B}}$ must be associated with uplift and cooling, not with primary intrusion.

Dunlop and Stirling [17] in their original study were unsure whether the Cordova A and B NRMs were of thermal or chemical/thermochemical origin. Chemical remanent magnetization (CRM) seemed to be favored by the ${ }^{40} \mathrm{Ar} /{ }^{39} \mathrm{Ar}$ ages [18], which pre-dated the $\sim 930$ and $\sim 820$ Ma magnetization ages indicated by comparing $\mathrm{CO}_{\mathrm{A}}$ and $\mathrm{CO}_{\mathrm{B}}$ paleopoles to the clockwise Grenville Loop. This discrepancy can be reconciled, as explained above, by a counterclockwise Grenville Loop, which implies an age older than $980 \mathrm{Ma}$ for $\mathrm{CO}_{\mathrm{A}}$, perhaps $1000-1020 \mathrm{Ma}$. The match to regional ${ }^{40} \mathrm{Ar} /{ }^{39} \mathrm{Ar}$ hornblende ages is close [14,15]. These ages date the time the Cordova pluton and its surroundings passed through $\sim 500^{\circ} \mathrm{C}$ during regional cooling. The Cordova A laboratory unblocking temperatures are typically $525-570^{\circ} \mathrm{C}$ (see Fig. 8), which when corrected for the difference between laboratory and natural cooling time scales [23] translates to blocking temperatures of $\sim 500-550^{\circ} \mathrm{C}$ during regional cooling. Thus there is good reason to believe that the Cordova $\mathrm{A}$ is a thermal overprint acquired around 1000-1020 Ma, i.e. a TRM (although not the primary TRM).

The best evidence for the nature of the Cordova B NRM comes from its typical laboratory $T_{\mathrm{UB}}$ range, which is $300-500^{\circ} \mathrm{C}$ and does not overlap the A unblocking range (Figs. 3 and 8 ). The samples used for our present paleointensity work have clearer thermal demagnetization trajectories than the $A+B$ samples examined by Dunlop and Stir- 
(a)

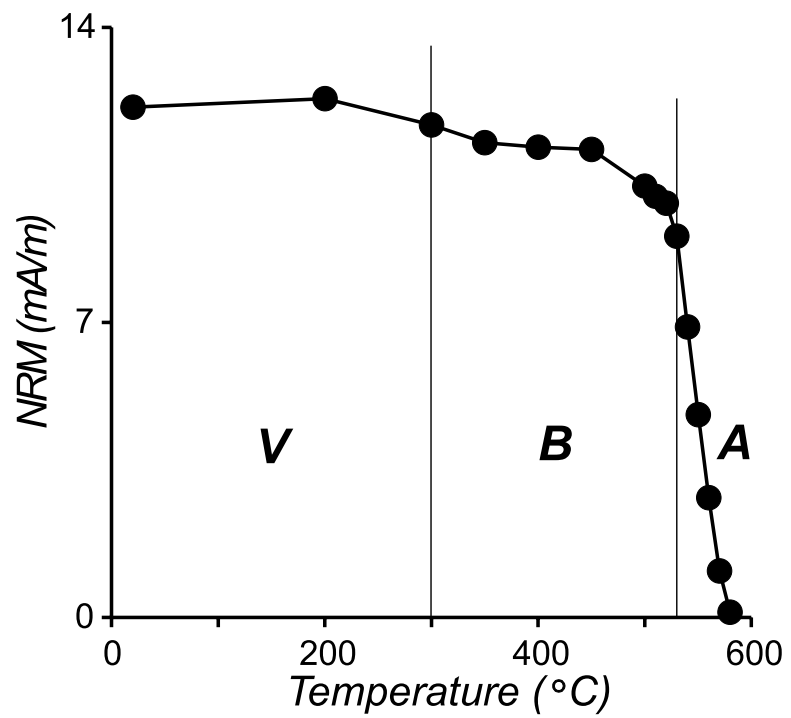

(b)

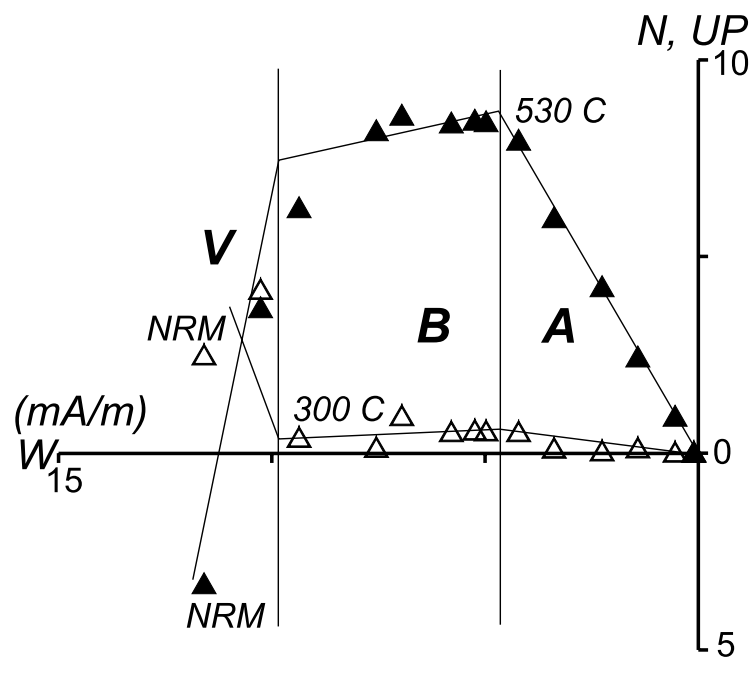

Fig. 3. An example of thermal demagnetization data, illustrating the separation of viscous remanence in the direction of the present Earth's field (V), the B magnetization (B), and the A remanence (A). In the vector plot of (b), open and solid triangles represent vertical- and horizontal-plane projections, respectively.

ling [17]. There are sharp junctions between $\mathrm{A}$ and $\mathrm{B}$ trajectories on vector diagrams for all the samples we used (otherwise it would not have been possible to make multivectorial paleointensity determinations, as explained later). Such sharp junctions are evidence that B is a pTRM, thermally overprinting A. A CRM overprint would produce rounded junctions with significant overlap of $\mathrm{B}$ and $\mathrm{A} T_{\mathrm{UB}} \mathrm{S}[24,25]$.

\section{Samples and magnetic properties}

We collected 90 oriented block samples from 12 sites (Fig. 1b) with multivectorial A+B remanences [17]. Of 700 specimens prepared, 186 pilot specimens were used for alternating-field (AF) and thermal demagnetization. Then 229 specimens whose sister specimens had median destructive fields $>30 \mathrm{mT}$ were selected for paleointensity experiments.

Fig. 3 is an example of the clean separation of $\mathrm{A}$ and $\mathrm{B}$ remanences by thermal demagnetization. A viscous present Earth's field overprint was removed by thermal cleaning to at most $300^{\circ} \mathrm{C}$. The
B NRM demagnetizes in the $T_{\mathrm{UB}}$ range $\sim 300$ $500^{\circ} \mathrm{C}$. On vector diagrams, B typically has NW declination and shallow inclination, usually between $-25^{\circ}$ and $+15^{\circ}$. The A NRM demagnetizes over the range $525-580^{\circ} \mathrm{C}$ and has $\mathrm{W}$ to $\mathrm{NW}$ declination and intermediate to steep upward inclination. The sharp junction between the $\mathrm{A}$ and $\mathrm{B}$ vectors around $520-530^{\circ} \mathrm{C}$ during thermal demagnetization implies that $\mathrm{B}$ is a pTRM overprinting A.

Room-temperature hysteresis in a maximum field of $0.5 \mathrm{~T}$ was measured on an alternatinggradient force magnetometer. Saturation magnetization $\left(M_{\mathrm{S}}\right)$, saturation remanent magnetization $\left(M_{\mathrm{rs}}\right)$, and coercive force $\left(H_{\mathrm{c}}\right)$ were determined from the hysteresis loops after paramagnetic high-field slope correction. Remanence coercivity $\left(H_{\mathrm{cr}}\right)$ was obtained from backfield measurements. Hysteresis loops were obtained for 54 chips, three from each of the 18 accepted specimens (see Section 8). $M_{\mathrm{rs}} / M_{\mathrm{s}}$ and $H_{\mathrm{cr}} / H_{\mathrm{c}}$ values are in the ranges $0.24-0.41$ and $1.46-2.19$, and lie in the single-domain (SD) to pseudo-SD (PSD) region of the Day et al. [26] plot (Fig. 4a).

Curie points $\left(T_{\mathrm{C}}\right)$ were estimated from the tem- 

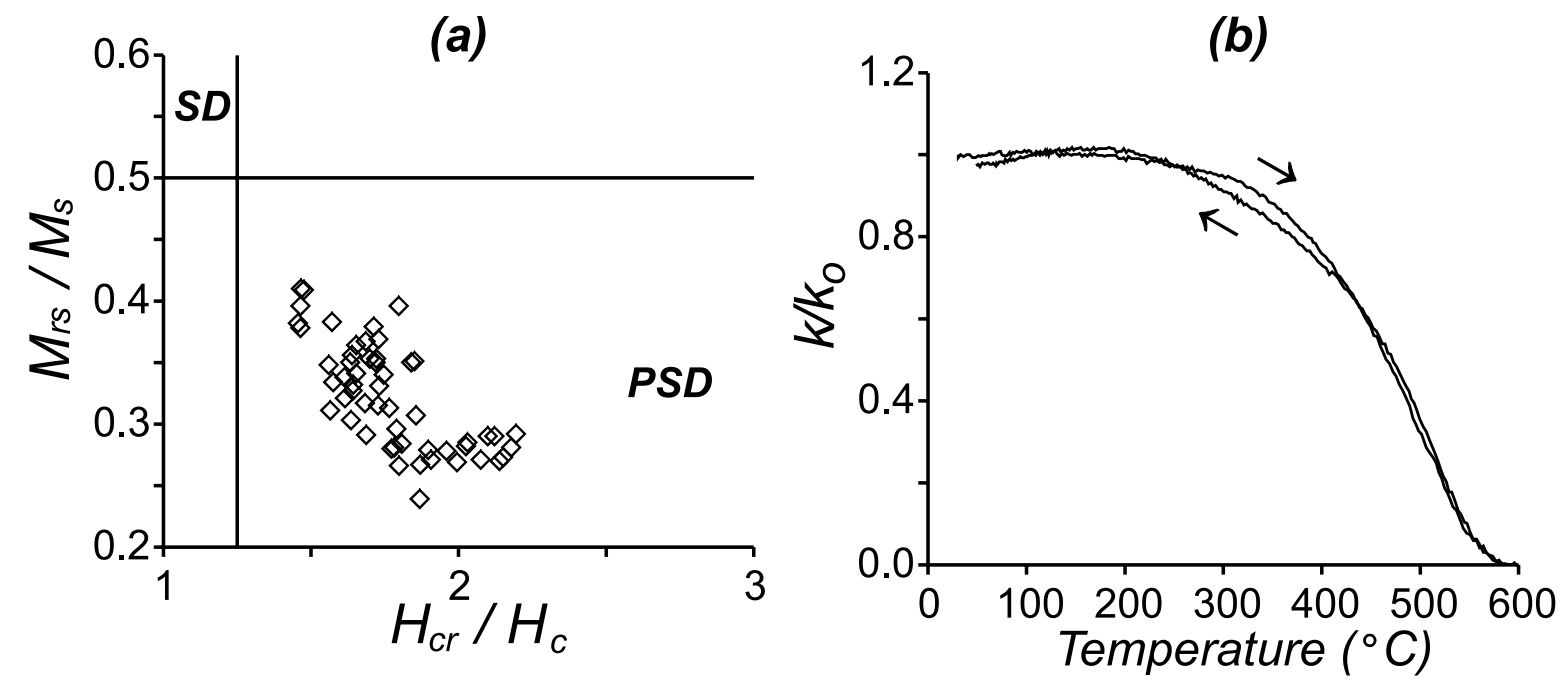

Fig. 4. (a) Hysteresis parameters $M_{\mathrm{rs}} / M_{\mathrm{s}}$ and $H_{\mathrm{cr}} / H_{\mathrm{c}}$ on a Day plot. The points fall in the SD and small PSD region for magnetite. (b) An example of a susceptibility-temperature curve, showing the Curie point $T_{\mathrm{C}}$ of magnetite.

perature dependence of weak-field susceptibility $k$, measured in air with a KLY-2 Kappabridge at the Institute for Rock Magnetism, University of Minnesota. The thermomagnetic behavior is practically reversible (Fig. 4b) with $T_{\mathrm{C}}$ near $580^{\circ} \mathrm{C}$, indicating Ti-free magnetite.

Although the $\mathrm{A}$ and $\mathrm{B}$ remanences are not primary NRMs, they are promising candidates for paleointensity determination. Based on shapes of AF demagnetization curves, hysteresis parameters, and $T_{\mathrm{C}}$ and maximum $T_{\mathrm{UB}}$ results, $\mathrm{A}$ and $B$ are carried by SD or fairly small PSD magnetites (Figs. 3 and 4). In thin sections, Dunlop and Stirling [17] observed fine 'dusty' magnetite in pyroxene crystals. Plagioclase was only slightly to moderately sericitized, and saussuritization of plagioclase and uralitization of pyroxene were seldom observed. In further thin-section work on the present samples, we consistently found that magnetite was in the form of ultrafine (a few $\mu \mathrm{m}$ or less) equant to elongated crystals encapsulated within (and therefore protected from alteration by) pyroxene and plagioclase hosts. This mode of occurrence of magnetite has been reported for many gabbros and anorthosites [27]. Ilmenite was common in thin sections but there were no obvious intergrowths with titanomagnetite. Titanium seems to have been taken up en- tirely by ilmenite. The Ti-free magnetite carrying $\mathrm{A}$ and $\mathrm{B}$ magnetizations precipitated from pyroxene and plagioclase, probably in initial cooling of the Cordova pluton. It is likely that A and B remagnetization events simply replaced pre-existing NRM up to a blocking temperature $T_{\mathrm{B}}$ corresponding to the peak reheating temperature, without forming new magnetic minerals. Although one cannot entirely rule out secondary magnetite formed by metamorphic reactions, there was no obvious indication of such magnetite along boundaries of other minerals and indeed alteration of the minerals was minor, as noted above.

\section{Multivectorial paleointensity methodology}

\subsection{Modeling}

Arai plots [28] of NRM remaining vs. pTRM gained in double heatings are widely used in Thellier-type paleointensity determination. Linearity of the Arai plot, along with univectorial decay of the NRM and statistical criteria (see Section 7), are the usual requirements for successful paleointensity determination. If the NRM consists of more than one vector, and if these vectors are 


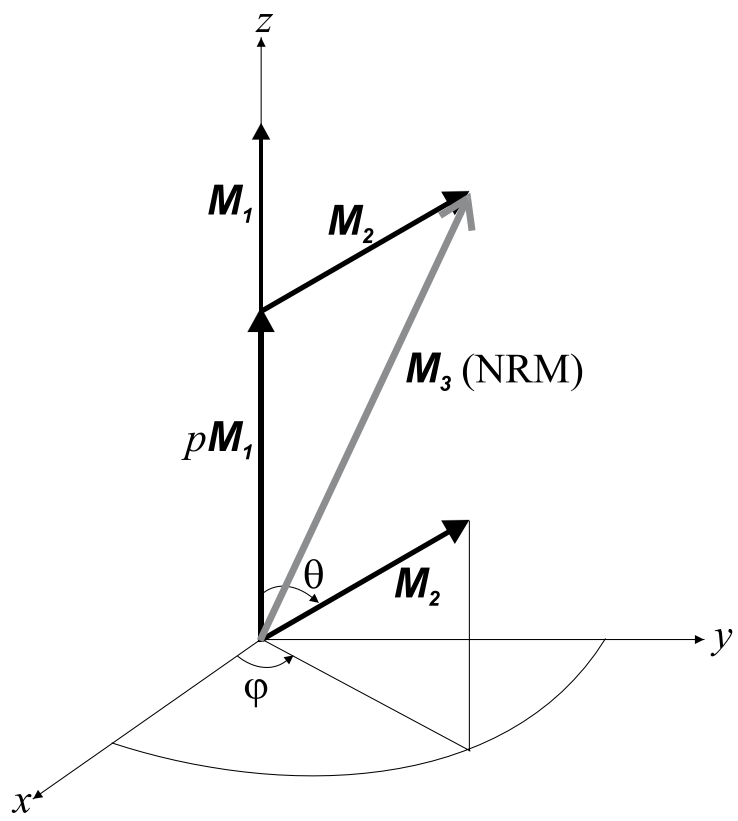

Fig. 5. A schematic in spherical coordinates of $\boldsymbol{M}_{\mathbf{1}}$, the NRM before remagnetization, $p \boldsymbol{M}_{\mathbf{1}}$, the part of $\boldsymbol{M}_{\mathbf{1}}$ that survives remagnetization, and $\boldsymbol{M}_{\mathbf{2}}$, the thermal overprint. $\theta$ and $\varphi$ are the polar and azimuthal angles.

cleanly resolved in thermal demagnetization, as is the case for the Cordova A and B remanences, it should be possible to determine a paleofield intensity for each vector separately. However, the usual Arai plot is not well suited to this application because the NRM plotted is the vector sum of $\mathbf{A}+\mathbf{B}$, which is smaller (sometimes much smaller) than the scalar sum A+B. The slope of the lowtemperature portion of the Arai plot will not give the correct B paleofield intensity, and may not even be linear.

To simplify the modeling, we assume ideal SD behavior, ensuring that the Thellier laws of additivity, reciprocity and independence of pTRMs are obeyed. We ignore the possible effect of viscous overprinting.

The sample originally acquired TRM $\boldsymbol{M}_{\mathbf{1}}$ parallel to paleofield $\boldsymbol{H}_{\mathbf{1}}$. For convenience, the direction of $\boldsymbol{M}_{1}$ and $\boldsymbol{H}_{1}$ is taken as the $z$ axis of a spherical coordinate system, and $M_{1}$ (the TRM intensity) is set to 1 (Fig. 5). Thus in Cartesian coordinates, $\boldsymbol{M}_{\mathbf{1}}$ has components $[0,0,1]$.

In nature, a later heating event erased fraction $(1-p)$ of $\boldsymbol{M}_{1}$ and replaced it by $\boldsymbol{M}_{2}$, leaving a surviving fraction $p$ of $\boldsymbol{M}_{\mathbf{1}}$ after remagnetization. The thermal overprint vector $\boldsymbol{M}_{\mathbf{2}}$ produced by the later paleofield $\boldsymbol{H}_{2}$, whose strength $\mathrm{H}_{2}$ is a fraction $r$ of $H_{1}$, then has components $r(1-p)[\sin \theta$ $\cos \varphi, \sin \theta \sin \varphi, \cos \theta]$ where $\theta$ is the polar angle between $\boldsymbol{M}_{\mathbf{1}}$ and $\boldsymbol{M}_{\mathbf{2}}$ and $\varphi$ is the azimuthal angle in the $x y$-plane from the positive $x$-axis (Fig. 5). We have assumed that $M$ is proportional to $H$.

After remagnetization, the total NRM $\boldsymbol{M}_{3}$ is the vector sum of $\boldsymbol{M}_{\mathbf{2}}$ and $p \boldsymbol{M}_{\mathbf{1}} . \boldsymbol{M}_{\mathbf{3}}$ thus has components $[r(1-p) \sin \theta \cos \varphi, r(1-p) \sin \theta \sin \varphi$, $r(1-p) \cos \theta+p]$. We consider below some special cases where $\theta$ has particular values of practical interest, and the Arai plots that result:

Case 1: $\left(\theta=180^{\circ}\right) \rightarrow \mathbf{M}_{3}=[0,0, p-r(1-p)]$.

This represents remagnetization after a field reversal. The total NRM has normal or reversed
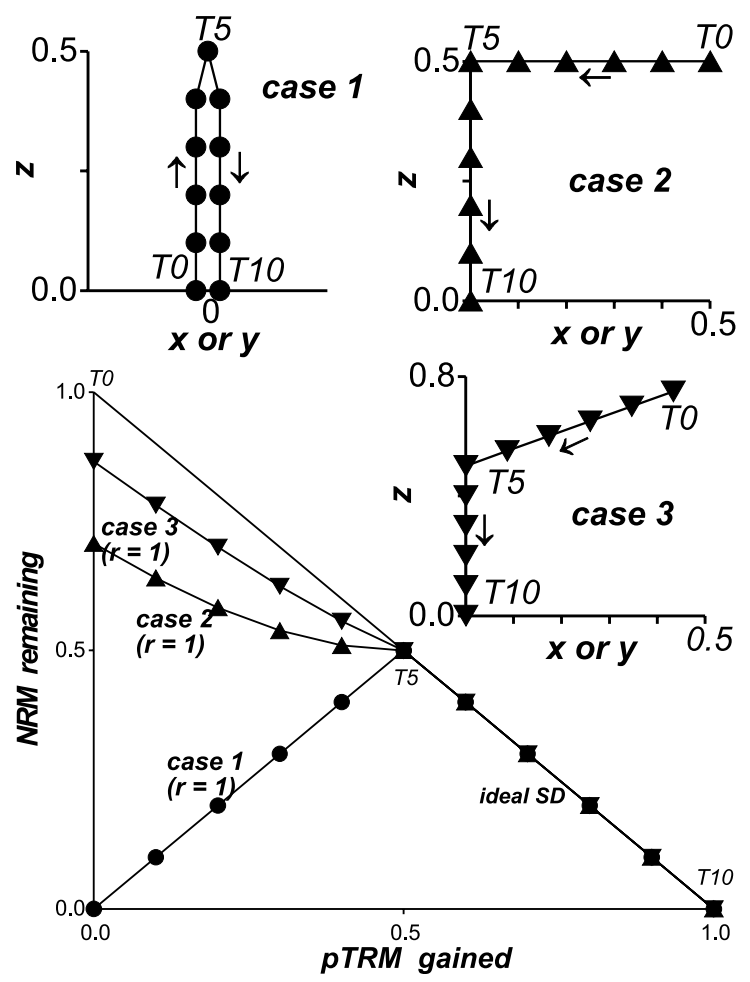

Fig. 6. Simulated conventional Arai plots for antiparallel, perpendicular, and oblique $\left(60^{\circ}\right)$ overprinting of $\boldsymbol{M}_{\mathbf{1}}$ by $\boldsymbol{M}_{2}$ at a reheating temperature $T_{5}(r=1)$. Only in the antiparallel case does the thermal demagnetization of $\boldsymbol{M}_{\mathbf{2}}$ between $T_{0}$ and $T_{5}$ result in a straight line. 
(a)

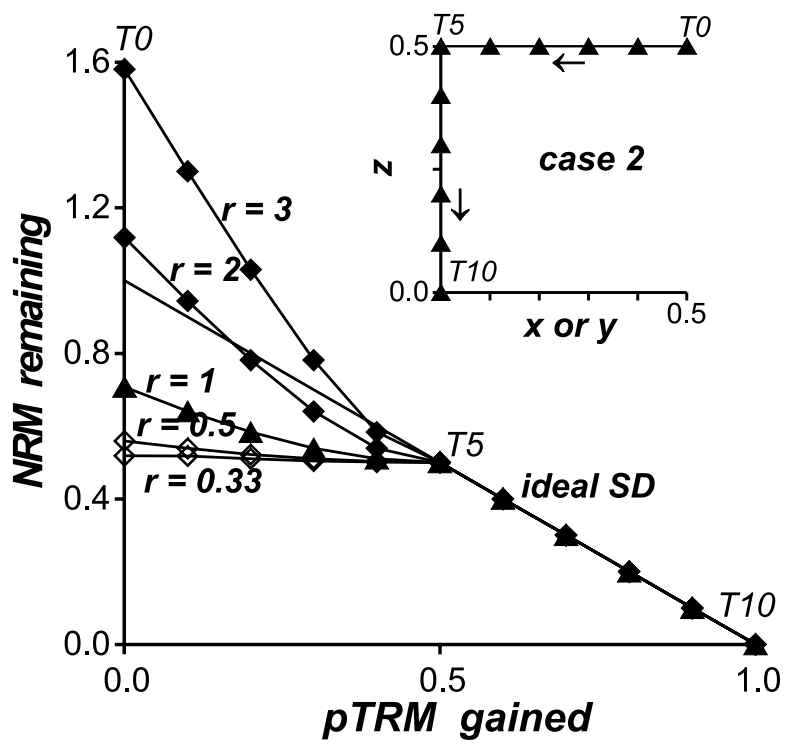

(b)

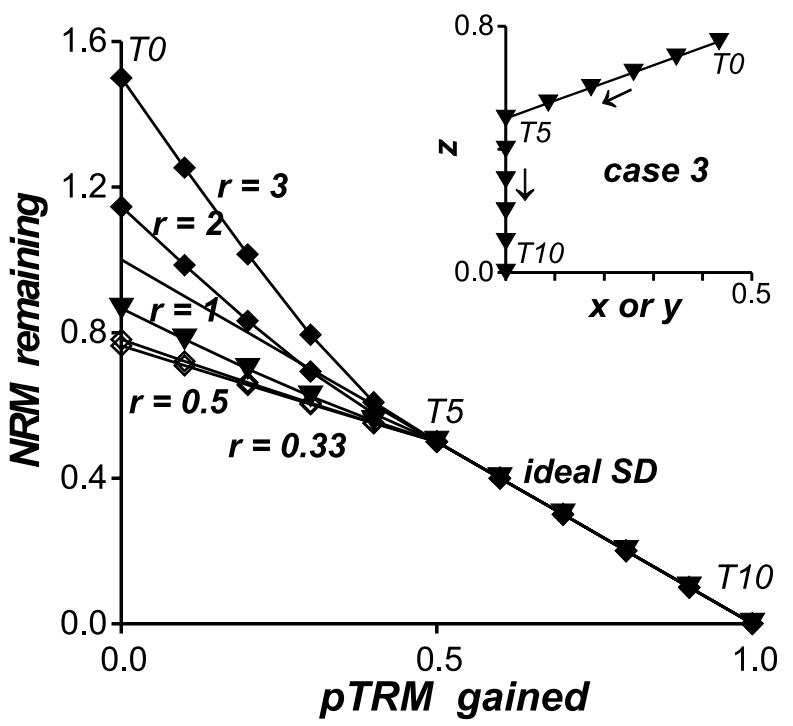

Fig. 7. Simulated conventional Arai plots for overprinting of $\boldsymbol{M}_{\mathbf{1}}$ by $\boldsymbol{M}_{\mathbf{2}}$ at angles of (a) $90^{\circ}$ and (b) $60^{\circ}$, for various values of the field ratio $r$. In all cases, the thermal demagnetization of $\boldsymbol{M}_{\mathbf{2}}$ between $T_{0}$ and $T_{5}$ results in a curved, rather than a straight, line. The average slope of this segment always gives a low paleointensity $\mathrm{H}_{2}$.

polarity for $p>0.5$ or $<0.5$, respectively, if $r=1$ (fields $H_{1}$ and $H_{2}$ have the same strength).

$$
\text { Case 2: } \quad\left(\theta=90^{\circ}\right) \rightarrow \boldsymbol{M}_{\mathbf{3}}=[r(1-p) \cos \varphi,
$$
$r(1-p) \sin \varphi, p]$.

In this case, $\boldsymbol{H}_{\mathbf{2}}$ and $\boldsymbol{H}_{\mathbf{1}}$ are perpendicular, and $\boldsymbol{M}_{\mathbf{3}}$ is the sum of orthogonal vectors $\boldsymbol{M}_{\mathbf{2}}$ and $p \boldsymbol{M}_{\mathbf{1}}$.

Case 3: $\left(\theta=60^{\circ}\right) \rightarrow \boldsymbol{M}_{\mathbf{3}}=[(1 / 2) r(1-p) \sqrt{3} \cos \varphi$, $(1 / 2) r(1-p) \sqrt{3} \sin \varphi, p+(1 / 2) r(1-p)]$.

This case models the Cordova Gabbro, whose mean $\mathrm{A}$ and $\mathrm{B}$ inclinations differ by $\sim 60^{\circ}$.

\subsection{Multivectorial paleointensity simulations}

We now simulate Thellier-type paleointensity determination for a bivectorial NRM $\boldsymbol{M}_{\mathbf{3}}=$ $p \boldsymbol{M}_{\mathbf{1}}+\boldsymbol{M}_{\mathbf{2}}$ using 10 temperature steps $T_{i}$, chosen so that each zero-field heating step destroys $10 \%$ of $\boldsymbol{M}_{1}$. According to the pTRM reciprocity law, these $T_{i}$ also produce $10 \%$ increments of pTRM in field-on cooling steps. Thus, for $\boldsymbol{M}_{\mathbf{1}}$ alone, NRM remaining versus pTRM acquired for $T_{i}=1, \ldots, 10$ follows the ideal SD line on the Arai plot, with equally spaced points.

For simplicity, suppose that thermal remagne- tization reached a peak temperature $T_{5}$, so that $p=0.5$ (ignoring differences between blocking temperatures on natural and laboratory time scales). Thus if the ratio of field magnitudes $r=H_{2} / H_{1}=1$, the intensity of $\boldsymbol{M}_{2}$ is one-half that of $\boldsymbol{M}_{1}$, and $\boldsymbol{M}_{\mathbf{3}}$ consists of two vectors $\boldsymbol{M}_{\mathbf{2}}$ and $p \boldsymbol{M}_{1}$ of equal magnitude with non-overlapping blocking/unblocking ranges $T_{0}-T_{5}$ and $T_{5}-$ $T_{10}$, respectively. Heating steps $T_{1}-T_{5}$ demagnetize equal 20\% increments of $\boldsymbol{M}_{\mathbf{2}}$ and steps $T_{6}-T_{10}$ demagnetize $20 \%$ increments of $p \boldsymbol{M}_{\mathbf{1}}$.

Simulated Arai plots for cases 1-3 when $H_{2}=H_{1}$ are illustrated in Fig. 6. The field for pTRM production was also $H_{1}$, so that all graphs have slope -1 from $T_{5}$ to $T_{10}$. Remagnetization at $T_{5}$ in a field $\boldsymbol{H}_{2}$ of reverse polarity (case 1) results in a triangular-shaped Arai plot with the correct slope +1 from $T_{0}$ to $T_{5}$. Remagnetization in a perpendicular field (case 2) or at $60^{\circ}$ to $\boldsymbol{H}_{\mathbf{1}}$ (case 3) results in non-linear segments from $T_{0}$ to $T_{5}$ whose average slopes are considerably less than -1 . Case 3 , which is relevant for the Cordova Gabbro $\mathrm{B}$, is insidious because the curvature is slight and might not be noticed with real data. 
The true paleointensity $\mathrm{H}_{2}$ is about $35 \%$ higher than the average slope of this segment.

Cases 2 and 3 are further simulated in Fig. 7 to demonstrate the effect of remagnetization in fields of four different intensities: $r=0.33,0.5,2$, and 3 . Compared to the ideal line for a single NRM vector, the Arai plots of these bivectorial NRMs deviate from linearity at low temperatures and have slopes that underestimate the overprinting field $\mathrm{H}_{2}$. Clearly, the problem is not with the behavior of the overprint $\boldsymbol{M}_{\mathbf{2}}$ but with using a single Arai plot for the sum of two (or in principle several) vectors. The solution is to construct an individual Arai plot for each vector.

In practice, constructing separate Arai plots requires a priori information, namely the remagnetization temperature $T^{*}$ ( $T_{5}$ in our modeling) at which $\boldsymbol{M}_{\mathbf{2}}$ and $p \boldsymbol{M}_{\mathbf{1}}$ have a sharp junction in vector projections. The junction temperature is less easily picked directly from the Arai plot. The NRM remaining at $T^{*}$ (namely $p \boldsymbol{M}_{\mathbf{1}}$ ) is vectorial- ly subtracted from all NRMs $\boldsymbol{M}_{\mathbf{3}}$ for heating steps $T_{i}<T^{*}$, giving adjusted values $\mathrm{NRM}^{*}$ (namely $\boldsymbol{M}_{2}$ ). No adjustment is needed for pTRMs because these are acquired in the same laboratory field direction below and above $T^{*}$. Then the Arai plot for $\boldsymbol{M}_{2}$ is $\mathrm{NRM}^{*}$ vs. pTRM, over the range $T_{0}$ to $T^{*}$. The Arai plot for $p \boldsymbol{M}_{\mathbf{1}}$, over the range $T^{*}$ to $T_{\mathrm{C}}$, is $\mathrm{NRM}$ vs. [pTRM-pTRM $\left.\left(T^{*}\right)\right]$. The latter subtraction is a simple scalar one.

\section{Paleointensity experiments and results}

The first set of 169 specimens was heated in air following the Coe-modified Thellier method [29]. Zero-field and in-field $\left(H_{\mathrm{lab}}=60 \pm 1.2 \mu \mathrm{T}\right)$ heatings were carried out in $50^{\circ} \mathrm{C}$ steps from $300^{\circ} \mathrm{C}$ to $500^{\circ} \mathrm{C}$, then in $10^{\circ} \mathrm{C}$ steps to $580^{\circ} \mathrm{C}$, using an MMTD furnace. pTRM checks were made at every other heating step. The same procedures were followed for the second set of 60 specimens,

Table 1

Paleointensity determinations for the A magnetization ${ }^{\mathrm{a}}$

\begin{tabular}{|c|c|c|c|c|c|c|c|c|}
\hline Site/Sample & Atm. & $N$ & $\begin{array}{l}\Delta T \\
\left({ }^{\circ} \mathrm{C}\right)\end{array}$ & $\begin{array}{l}H \pm \sigma \\
(\mu \mathrm{T})\end{array}$ & $f$ & $g$ & $S^{\prime}$ & $q$ \\
\hline $1 / 5 \mathrm{~B} 2$ & A & 6 & $530-580$ & $18.83 \pm 1.36$ & 0.99 & 0.69 & 0.557 & 9.46 \\
\hline $2 / 6 \mathrm{Cl}$ & A & 6 & $530-580$ & $18.05 \pm 1.27$ & 0.90 & 0.82 & 0.447 & 10.49 \\
\hline $2 / 7 \mathrm{C} 1$ & A & 6 & $530-580$ & $17.21 \pm 1.09$ & 0.87 & 0.81 & 0.728 & 11.13 \\
\hline 2/8B1 & A & 6 & $530-580$ & $16.73 \pm 1.20$ & 0.88 & 0.84 & 0.674 & 10.31 \\
\hline 2/9B1 & A & 6 & $530-580$ & $17.43 \pm 1.17$ & 0.97 & 0.76 & 0.233 & 10.98 \\
\hline $3 / 12 \mathrm{~A} 1$ & A & 6 & $530-580$ & $16.10 \pm 1.17$ & 0.96 & 0.82 & 0.976 & 10.83 \\
\hline 3/12B1 & $\mathrm{H}$ & 6 & $530-580$ & $16.14 \pm 1.14$ & 0.93 & 0.83 & 1.104 & 10.93 \\
\hline 4/16A1 & A & 5 & $540-580$ & $24.41 \pm 1.84$ & 0.97 & 0.67 & 1.263 & 8.62 \\
\hline $4 / 16 \mathrm{C} 1$ & $\mathrm{H}$ & 5 & $540-580$ & $19.30 \pm 1.58$ & 0.92 & 0.82 & 0.775 & 9.22 \\
\hline 4/17A1 & $\mathrm{H}$ & 5 & $540-580$ & $18.07 \pm 1.15$ & 0.99 & 0.73 & 0.067 & 11.36 \\
\hline 4/17B1 & A & 5 & $540-580$ & $15.53 \pm 0.97$ & 1.00 & 0.69 & 0.280 & 11.05 \\
\hline 4/18A1 & A & 6 & $530-580$ & $19.02 \pm 1.74$ & 0.98 & 0.73 & 0.192 & 7.82 \\
\hline 4/18A2 & $\mathrm{H}$ & 6 & $530-580$ & $15.25 \pm 1.11$ & 0.93 & 0.74 & 0.327 & 9.46 \\
\hline $5 / 27 \mathrm{~B} 1$ & $\mathrm{~A}$ & 6 & $530-580$ & $19.03 \pm 1.73$ & 0.94 & 0.75 & 0.205 & 7.76 \\
\hline $5 / 27 \mathrm{C} 1$ & $\mathrm{H}$ & 6 & $530-580$ & $19.42 \pm 1.83$ & 0.95 & 0.77 & 0.688 & 7.76 \\
\hline $6 / 55-5$ & A & 6 & $530-580$ & $19.29 \pm 1.13$ & 0.92 & 0.8 & 0.919 & 12.56 \\
\hline $6 / 58-6$ & $\mathrm{~A}$ & 6 & $530-580$ & $18.68 \pm 1.26$ & 0.88 & 0.83 & 0.201 & 10.83 \\
\hline 6/95-6 & $\mathrm{H}$ & 6 & $530-580$ & $17.63 \pm 1.29$ & 0.93 & 0.83 & 0.494 & 10.55 \\
\hline Mean paleointensity ${ }^{\mathrm{b}}$ & & & & $18.12 \pm 2.07$ & & & & \\
\hline Mean inclination & & & & $-59.5^{\circ}\left(\alpha_{95}=4.8^{\circ}\right)$ & & & & \\
\hline VADM & & & & $(3.12 \pm 0.36) \times 10^{22} \mathrm{~A} \mathrm{~m}^{2}$ & & & & \\
\hline
\end{tabular}

a Atm. is the heating atmosphere: A, air, $\mathrm{H}$, helium; $N$ is the number of points used in paleointensity determination; $\Delta T$ is the interval of temperature used in slope calculation; $f$ and $g$ are NRM fraction and gap factor, respectively [45]; $S^{\prime}$ is the quality factor defined by $\mathrm{Yu}$ et al. [46]; $H \pm \sigma$ are the estimated paleointensity and its standard error after AARM correction.

$\mathrm{b}$ The uncertainty in the mean is the standard deviation rather than the commonly used standard error [45]. 

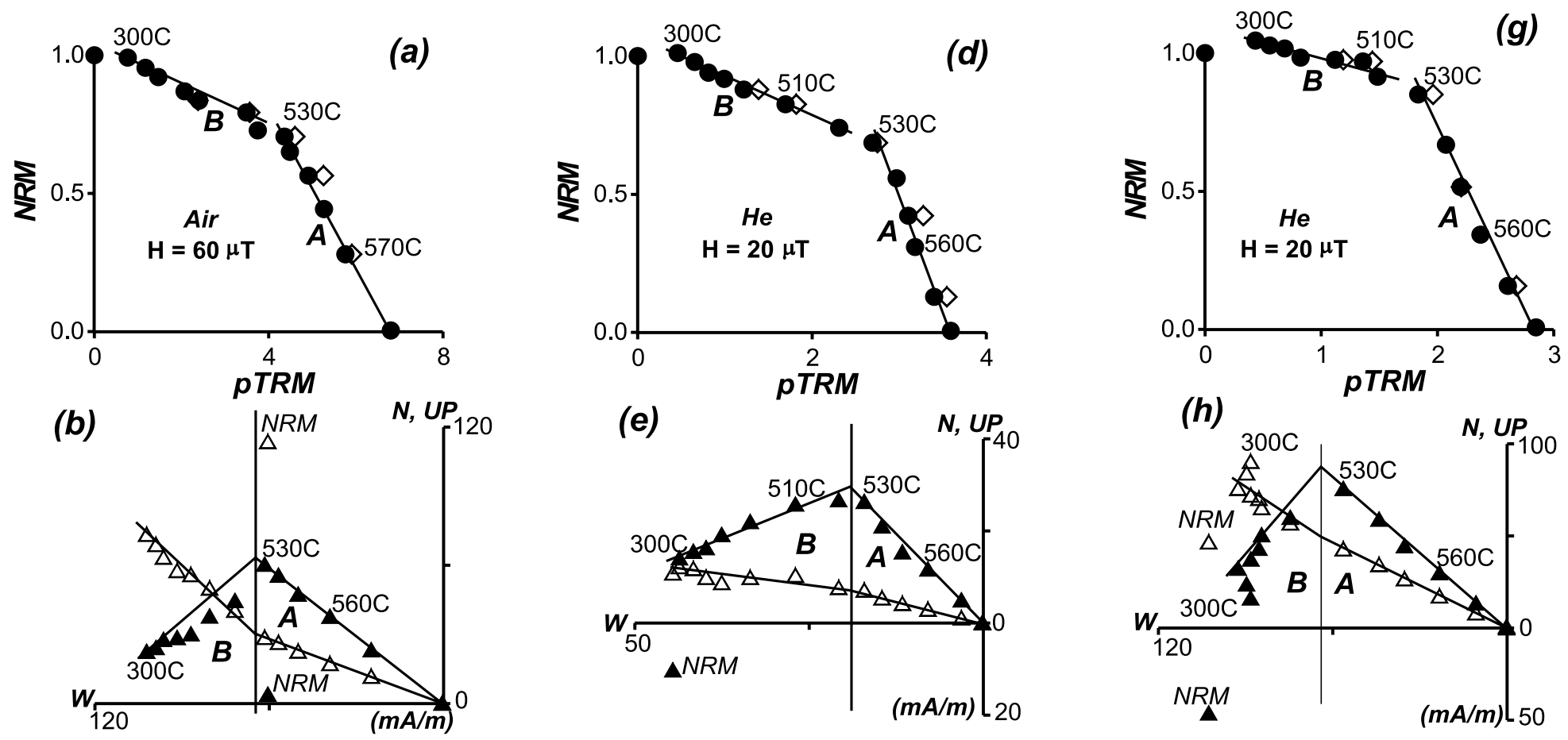

怘
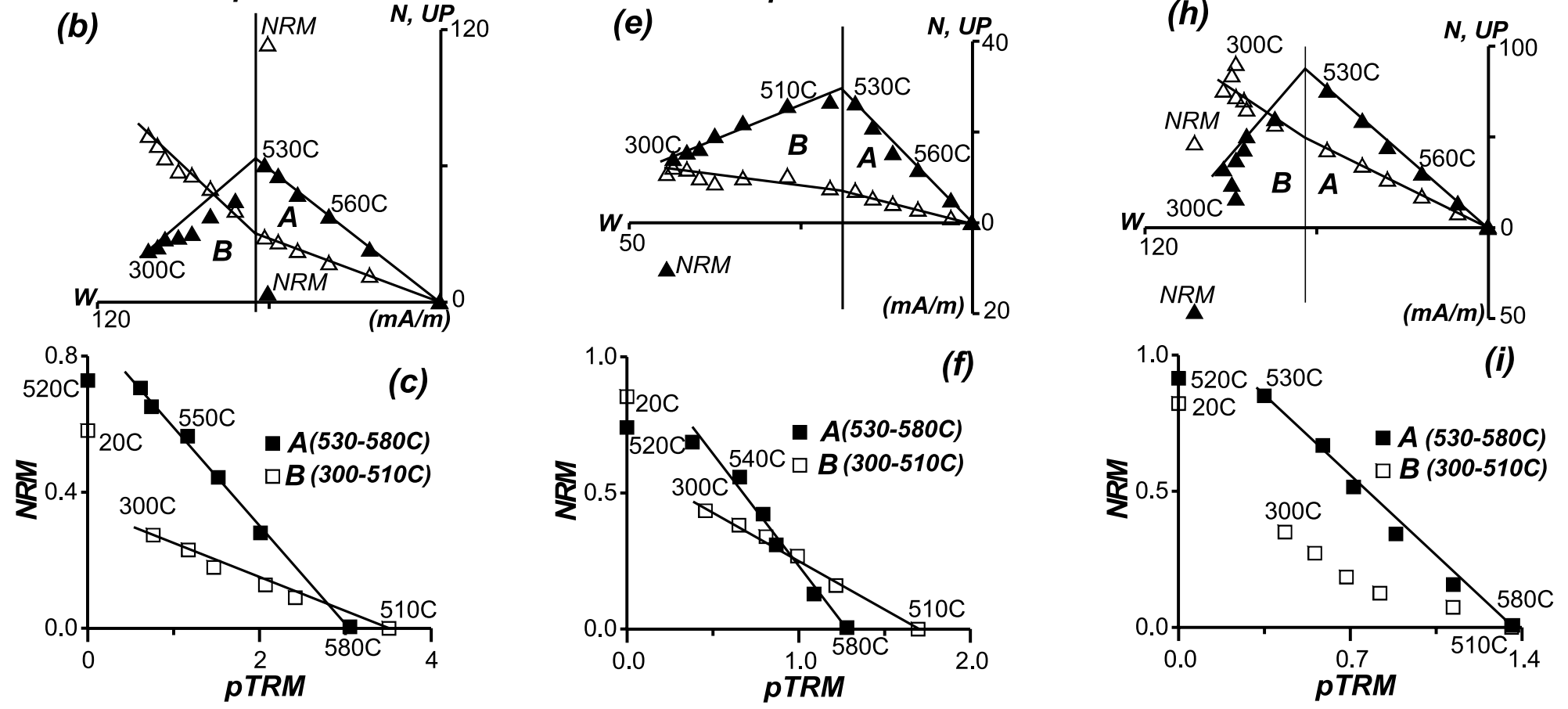

Fig. 8. Representative paleointensity determinations on conventional Arai plots (a,d,g) and on vectorially reconstructed Arai plots (c,f,i). Vector projections of the NRM thermal demagnetization data appear in (b,e,h), where open and solid triangles denote horizontal- and vertical-plane projections, respectively. Samples: (a-c) C9 B1, (d-f) C12 B1, (g-i) CG 95-6. The first two samples had successful paleointensity results for both A and B NRMs (c,f). For CG 95-6, only the A data gave a reliable paleointensity. 

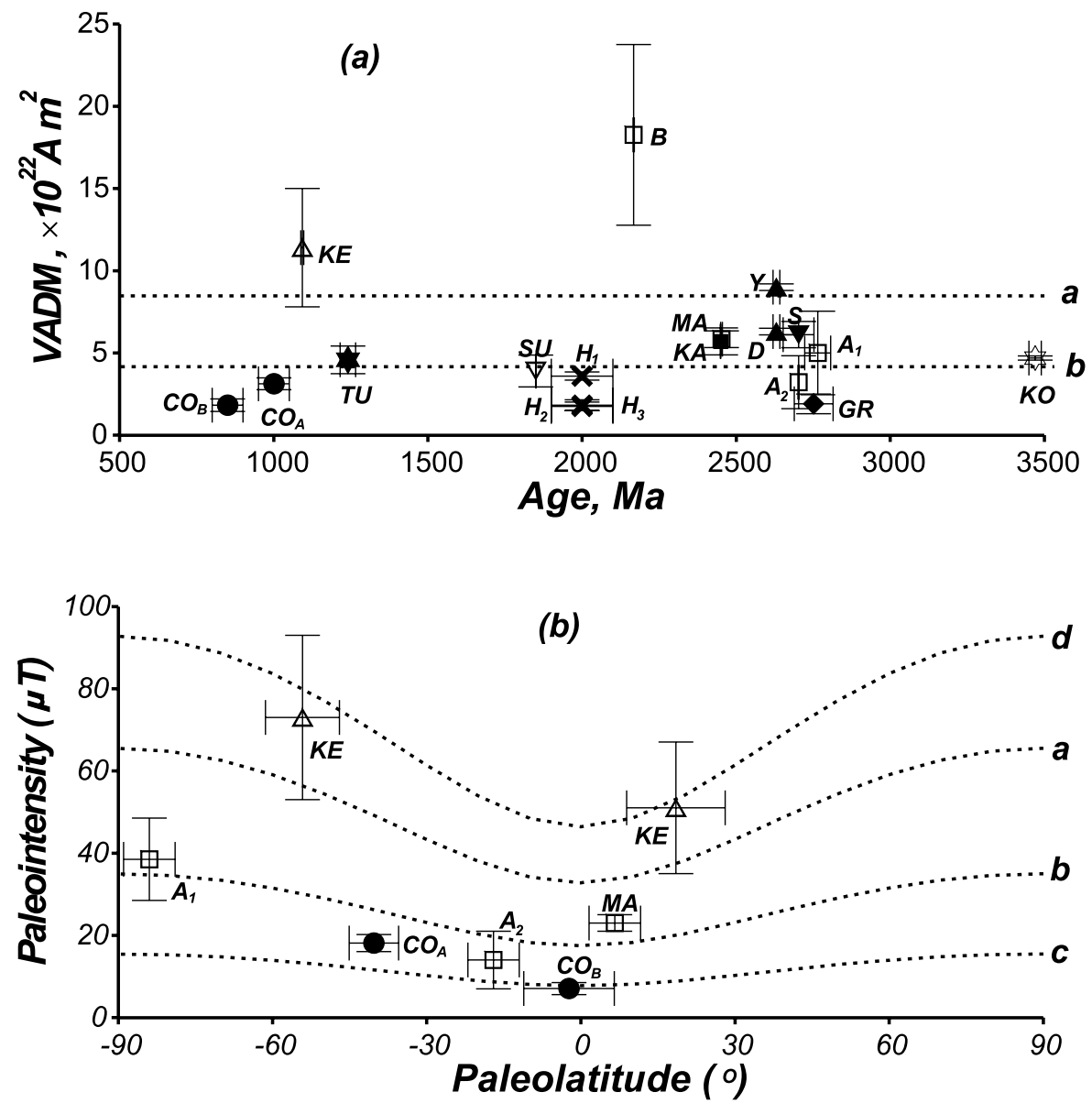

Fig. 9. (a) Precambrian VADMs from Thellier-type paleointensity results. CO: Cordova [this study]; KE: Keweenawan [34]; TU: Tudor [2]; SU: Sudbury [39]; H: Hamersley [37]; B: Biscotasing [35,36]; MA: Matachewan [40]; KA: Karelian [47]; Y: Yellowknife [44]; D: Dwyer [44]; S: Stillwater [30]; A: Abitibi [40]; GR: Greenland [49]; KO: Komati [48]. Lines a,b: mean dipole moment for the last $0.3 \mathrm{Ma}$ and for $0.3-300 \mathrm{Ma}$, respectively [30]. (b) Paleofield values as a function of paleolatitude, compared to the expected variation for an axial dipole field with various dipole moments: a-d: $8.5,4.5,2.0$ and $12 \times 10^{22}$ $\mathrm{Am}^{2}$.

heated in helium, but a lower field, $H_{\text {lab }}=20 \pm 0.2$ $\mu \mathrm{T}$, was used because the first set gave paleointensity values $\sim 20 \mu \mathrm{T}$. Temperatures were reproducible within $\pm 2^{\circ} \mathrm{C}$ and the residual field in the furnace during demagnetization steps was $<150$ nT. Bulk susceptibility was measured after each temperature step to detect possible chemical alteration.

In order to eliminate the effect of magnetic fabric anisotropy, anisotropy of anhysteretic remanent magnetization (AARM) was used as a correction technique [30]. ARM was produced in six successive directions $( \pm z, \pm x, \pm y)$ to obtain the AARM tensor, $R_{i j}(i, j=x, y, z)$.

A paleointensity result was accepted only when: (a) a linear segment on the Arai plot was defined by at least five points, with at least four successive pTRM checks in agreement within $10 \%$; (b) the points defining the line pass statistical rejection criteria (see Tables 1 and 2); (c) the NRM vector is stable in direction during thermal demagnetization, with no tendency to migrate towards the direction of $\boldsymbol{H}_{\mathrm{lab}}$; and (d) the bulk susceptibility remains constant to within $10 \%$ 
throughout the temperature range of the linear segment.

Fig. 8 gives examples of accepted paleointensity results. Fig. 8a,d,g gives conventional Arai plots for the total NRM $(A+B)$. As expected from the modeling (Figs. 6 and 7), they have two distinct segments: a curved portion for $T_{i}<525^{\circ} \mathrm{C}$ and a steeper linear segment for $T_{i}>525^{\circ} \mathrm{C}$. These are the same intervals over which the vector plots (Fig. 8b,e,h) show decay of the B and A remanences. The pTRM checks reproduce the original $500,510,530,550$ and $570^{\circ} \mathrm{C}$ pTRMs.

The reconstructed Arai plots (Fig. 8c,f,i) used $520^{\circ} \mathrm{C}$ as a junction temperature, $T^{*}$. Paleointensities for the $\mathrm{A}$ and $\mathrm{B}$ remanences were determined from the slopes of the $530-580^{\circ} \mathrm{C}$ and $300-510^{\circ} \mathrm{C}$ linear segments, respectively. For C9 $\mathrm{B} 1$ and $\mathrm{C} 12 \mathrm{~B} 1$ (Fig. 8c,f), both $\mathrm{A}$ and $\mathrm{B}$ remanences yielded reliable paleointensities, while $\mathrm{C} 95-$ 6 (Fig. 8i) had non-linear behavior for the B remanence. Incomplete removal of a viscous overprint may be responsible for this failure (see the 300 and $350^{\circ} \mathrm{C}$ points in Fig. 8h). Three specimens (C12 A1, C58-6, C95-6) fall in this category and did not yield acceptable B results. Overall, 18 reliable paleointensities were obtained for the A remanence and 15 paleointensity values for the $B$ remanence (Tables 1 and 2).

\section{Discussion}

\subsection{Cordova $A$ and $B$ paleointensities}

The A and B magnetizations of the Cordova Gabbro are secondary but ancient. We interpret A to be a totally reset TRM $(\sim 1000 \mathrm{Ma})$ and B a pTRM overprint ( $\sim 850 \mathrm{Ma})$ acquired during regional cooling following the Grenvillian orogeny. The evidence for a TRM/pTRM origin of $\mathrm{A}$ and $\mathrm{B}$ comes from rock magnetism, ${ }^{40} \mathrm{Ar} /{ }^{39} \mathrm{Ar}$ thermochronometry, and optical mineralogy. The A NRM demagnetizes in laboratory heating over a range that translates to a blocking temperature interval of $\sim 500-550^{\circ} \mathrm{C}$ in nature and the $\mathrm{CO}_{\mathrm{A}}$ paleopole is compatible with a magnetization age of $\sim 1000 \mathrm{Ma}$. The Cordova Gabbro indeed cooled through approximately these temperatures

Table 2

Paleointensity determinations for the $\mathrm{B}$ magnetization ${ }^{\mathrm{a}}$

\begin{tabular}{|c|c|c|c|c|c|c|c|}
\hline Site/Sample & $N$ & $\begin{array}{l}\Delta T \\
\left({ }^{\circ} \mathrm{C}\right)\end{array}$ & $\begin{array}{l}H \pm \sigma \\
(\mu \mathrm{T})\end{array}$ & $f$ & $g$ & $S^{\prime}$ & $q$ \\
\hline $1 / 5 \mathrm{~B} 2$ & 6 & $300-510$ & $5.67 \pm 0.43$ & 0.60 & 0.92 & 0.620 & 7.28 \\
\hline $2 / 6 \mathrm{C} 1$ & 6 & $300-510$ & $8.05 \pm 0.42$ & 0.40 & 0.96 & 0.179 & 7.36 \\
\hline $2 / 7 \mathrm{C} 1$ & 6 & $300-510$ & $7.25 \pm 0.44$ & 0.82 & 0.82 & 0.285 & 11.08 \\
\hline $2 / 8 \mathrm{~B} 1$ & 6 & $300-510$ & $7.69 \pm 0.74$ & 0.68 & 0.9 & 0.989 & 6.36 \\
\hline 2/9B1 & 6 & $300-510$ & $6.13 \pm 0.47$ & 0.47 & 0.95 & 0.794 & 5.82 \\
\hline 3/12B1 & 6 & $300-510$ & $7.26 \pm 0.52$ & 0.51 & 0.94 & 0.430 & 6.69 \\
\hline 4/16A1 & 6 & $300-510$ & $6.56 \pm 0.53$ & 0.41 & 0.96 & 0.236 & 4.87 \\
\hline $4 / 16 \mathrm{C} 1$ & 6 & $300-510$ & $4.30 \pm 0.33$ & 0.37 & 0.96 & 1.268 & 4.63 \\
\hline 4/17A1 & 6 & $300-510$ & $8.33 \pm 0.84$ & 0.53 & 0.93 & 0.795 & 4.89 \\
\hline 4/17B1 & 6 & $300-510$ & $5.19 \pm 0.64$ & 0.60 & 0.92 & 0.182 & 4.48 \\
\hline 4/18A1 & 6 & $300-510$ & $5.89 \pm 0.54$ & 0.51 & 0.94 & 1.577 & 5.23 \\
\hline 4/18A2 & 6 & $300-510$ & $6.74 \pm 0.57$ & 0.65 & 0.9 & 0.733 & 6.92 \\
\hline $5 / 27 \mathrm{~B} 1$ & 6 & $300-510$ & $8.64 \pm 0.69$ & 0.70 & 0.89 & 0.238 & 7.80 \\
\hline $5 / 27 \mathrm{C} 1$ & 6 & $300-510$ & $9.74 \pm 0.71$ & 0.74 & 0.88 & 0.636 & 8.93 \\
\hline $6 / 55-5$ & 6 & $300-510$ & $8.47 \pm 0.60$ & 0.62 & 0.92 & 1.433 & 8.07 \\
\hline Mean paleointensity ${ }^{\mathrm{b}}$ & & & $7.06 \pm 1.47$ & & & & \\
\hline Mean inclination & & & $-4.6^{\circ}\left(\alpha_{95}=8.8^{\circ}\right)$ & & & & \\
\hline VADM & & & $(1.82 \pm 0.38) \times 10^{22} \mathrm{~A} \mathrm{~m}^{2}$ & & & & \\
\hline
\end{tabular}

${ }^{a} N$ is the number of points used in paleointensity determination; $\Delta T$ is the interval of temperature used in slope calculation; $f$ and $g$ are NRM fraction and gap factor, respectively [45]; $S^{\prime}$ is the quality factor defined by Yu et al. [46]; $H \pm \sigma$ are the estimated paleointensity and its standard error after AARM correction.

$\mathrm{b}$ The uncertainty in the mean is the standard deviation rather than the commonly used standard error [45]. 
around $1000 \mathrm{Ma}$, as evidenced by ${ }^{40} \mathrm{Ar} /{ }^{39} \mathrm{Ar}$ hornblende ages in the Cordova area of 1000-1020 Ma $[14,15]$. Thus it is plausible that A is a TRM acquired when pre-existing minerals cooled through $550-500^{\circ} \mathrm{C}$, and not a CRM produced at lower temperatures in newly formed minerals. Thin section observations show minimal alteration of the silicate minerals and no indication of secondary magnetite rimming mineral grains. Rather, magnetite occurs as inclusions within pyroxene and plagioclase crystals, where it would have been protected from metamorphic fluids. In a similar way, the B magnetization age and blocking temperature range are broadly compatible with regional cooling ages recorded by muscovites [14]. In addition, sharp elbows between A and B thermal demagnetization trajectories imply that $\mathrm{B}$ is a thermal, not a chemical, overprint of A.

The Cordova $\mathrm{A}$ and $\mathrm{B}$ remanences record paleofield intensities of $18.1 \pm 2.1 \mu \mathrm{T}$ around 1000 $\mathrm{Ma}$ and $7.1 \pm 1.5 \mu \mathrm{T}$ around $850 \mathrm{Ma}$ (Tables 1 and 2). The remanence acquisition times are long in each case. In an earlier study in the same area, $\mathrm{Yu}$ and Dunlop [2] argued that the remanence of the Tudor Gabbro is a primary TRM with a cooling time of at most a few thousand years, giving a 'spot-reading' of the field around $1240 \mathrm{Ma}$. The cooling times for the Cordova $\mathrm{A}$ and $\mathrm{B}$ remanences must have been much longer than this, because large regions were affected. Not only has secular variation been averaged out, but also cyclic variations in paleofield intensity, which have periods of a few thousand years in historical and archeological records.

The time-averaged A and B paleofields, combined with mean $\mathrm{A}$ and $\mathrm{B}$ inclinations of $-60^{\circ}$ and $-5^{\circ}$, give virtual axial dipole moments $(\mathrm{VADMs})$ of $(3.12 \pm 0.36)$ and $(1.82 \pm 0.38) \times 10^{22}$ A $\mathrm{m}^{2}$, respectively (Tables 1 and 2 ). These are about $35 \%$ and $20 \%$ of the mean dipole moments of $8.8 \times 10^{22} \mathrm{~A} \mathrm{~m}^{2}$ for the last $10 \mathrm{ka} \mathrm{[31]} \mathrm{or}$ $8.47 \times 10^{22} \mathrm{~A} \mathrm{~m}^{2}$ for the last $0.3 \mathrm{Ma}$ [32] (line a in Fig. 9a). The recent field is unusually strong, however. A more reasonable comparison is with earlier fields. The A and B VADMs are about $70 \%$ and $40 \%$, respectively, of the mean dipole moments of $4.2 \times 10^{22} \mathrm{~A} \mathrm{~m}^{2}$ for the Cenozoic and Late Jurassic-Early Cretaceous [33] or $4.52 \times 10^{22} \mathrm{~A} \mathrm{~m}^{2}$ for the period $0.3-300 \mathrm{Ma}$ [32] (line $b$ in Fig. 9a). The Cordova results are therefore reasonable in terms of the overall record of Phanerozoic field intensities.

\subsection{Precambrian paleointensities and dipole moments}

VADMs from all Thellier-type paleointensity studies for the Precambrian are plotted in Fig. 9. Results that meet modern selection criteria, including pTRM checks, are given solid symbols. However, some earlier results obtained without pTRM checks are also of high quality. For example, the Keweenawan study of Pesonen and Halls [34] averaged large numbers of samples and included positive reversal and baked contact tests.

With only three exceptions, Precambrian VADMs lie within a range $\sim 0.5-1.5$ times the post-300 Ma Phanerozoic average field (line b). The Cordova $\mathrm{A}$ and $\mathrm{B}$ results are lower than the Tudor Gabbro VADM, which agrees closely with the average.

Larger contrasts in field intensity appear in two groups of five Late Proterozoic and 13 Late Archean and Early Proterozoic VADMs. The VADM from $\sim 1100$ Ma Keweenawan rocks [34] is 2-6 times higher than VADMs recorded between $\sim 850$ and $1240 \mathrm{Ma}$ ([2], this study). There is an even larger contrast between the VADM of $(18.3 \pm 5.5) \times 10^{22} \mathrm{~A} \mathrm{~m}^{2}$ for the 2167 Ma Biscotasing dikes [35,36] and nine VADMs from rocks 2000-2800 Ma in age, three VADMs from $\sim 2000$ Ma rocks of the Hamersley Basin, Australia [37], and the VADM of the $1850 \mathrm{Ma}$ Sudbury Norite [38]. The Biscotasing VADM has been cited as evidence for a rapid increase of geomagnetic field intensity caused by nucleation of Earth's inner core [36]. However, the Preissac result is based on only three specimens and has a large dispersion, whereas the much lower VADM of $(3.90 \pm 0.97) \times 10^{22} \mathrm{~A} \mathrm{~m}^{2}$ for the younger Sudbury Norite is based on 52 specimens and has low dispersion. Large fluctuations in VADMs are known from the Phanerozoic as well. Tarduno et al. [39] reported a VADM of $12.5 \times 10^{22}$ A $\mathrm{m}^{2}$ from the Rajmahal Traps 
(113-116 Ma), that is, three times the Cenozoic and Late Jurassic-Early Cretaceous average [33].

The Precambrian paleointensity data are plotted against paleolatitude in Fig. 9b. For comparison, the dashed lines depict intensity variations expected for an axial dipole field with dipole moments of $2.0,4.5,8.5$ and $12 \times 10^{22} \mathrm{~A} \mathrm{~m}^{2}$. There are three examples of results from rocks of similar ages magnetized at different paleolatitudes: the 2700-2760 Ma Abitibi metaperidotites, Abitibi gabbros and basalts, and $\sim 2470 \mathrm{Ma}$ Matachewan dikes (paleolatitudes of $-84,-17$ and $+7^{\circ}$ ) [36,40]; reverse and normal polarity Keweenawan rocks (age span $<22$ Ma [41], paleolatitudes of -55 and $+18^{\circ}$ ) [34]; and the Cordova Gabbro B and $\mathrm{A}$ (850 and $1000 \mathrm{Ma}$, paleolatitudes of -5 and $-60^{\circ}$ ). All three follow the expected dipole relation reasonably well, although the dipole moments indicated are much higher for the Keweenawan paleointensities than for the Abitibi or Cordova results. Based on this admittedly slender evidence, the Earth's field seems to have been dipolar at these times in the Precambrian.

\subsection{Multivectorial paleointensity determination}

Arai plots for multivectorial NRMs, both simulated (Figs. 6 and 7) and based on real data (Fig. 8a,d,g), bear a superficial resemblance to Arai plots associated with certain types of non-ideal behavior in the Thellier experiment. Multidomain (MD) and large PSD grains have thermal demagnetization 'tails': part of the pTRM produced at $T_{i}$ is not demagnetized by zero-field heating to $T_{i+1}$ and is effectively added to the 'NRM' at $T_{i+1}$ [42]. However, the pTRM has a different direction than the true NRM, with the result that the accumulation of such tails will progressively displace the 'NRM' direction measured in zero-field heating steps.

A different effect is CRM produced during infield heating/cooling steps. If the CRM appears parallel to the pTRM field $\boldsymbol{H}_{\text {lab }}$, it will augment the 'pTRM' intensity, producing a convex-down Arai plot, like those for thermal overprints when $r>1$ (Fig. 7). If CRM is coupled to the pre-existing NRM, it may produce convex-up results on the Arai plot [24,43], resembling our Arai simu- lations for $r<1$ (Fig. 7) and the Cordova data (Fig. 8). One major difference is that the non-linearity in our plots is confined to low temperatures, while that due to pTRM tails or laboratory-produced CRM is most pronounced at higher temperatures.

The ultimate fingerprint of thermal overprinting in nature is intersecting straight line segments in vector projections of thermal demagnetization data. Once this identification is made, it is easy to construct separate Arai plots for the two (or conceivably more) NRM vectors and test their individual linearity.

In addition to our Cordova work, two other recent Precambrian paleointensity studies [2,44] show multivectorial behavior consistent with thermal overprinting. All three studies reported convex-up data trends on conventional Arai plots and bivectorial decay of perpendicular or oblique NRM vectors. Paleointensity values for the thermal overprints could not be obtained in the other two studies because the overprint directions were not as well grouped as the Cordova B.

\section{Conclusions}

1. Conventional Arai plots distort the data for the lower- $T_{\mathrm{UB}}$ component in a multivectorial NRM. If thermal demagnetization data form two linear segments in vector projections (indicating a purely thermal overprint), separated Arai plots for the two component vectors will give an undistorted picture of the paleointensity data for both.

2. By this method, we have obtained reliable Thellier paleointensity values for the $\sim 1000$ $\mathrm{Ma} \mathrm{A}$ and $\sim 850 \mathrm{Ma} \mathrm{B}$ remanences of the Cordova Gabbro of southern Ontario. Eighteen reliable $A$ results give a VADM of $(3.12 \pm 0.36) \times 10^{22} \mathrm{~A} \mathrm{~m}^{2}$. From 15 reliable $\mathrm{B}$ results, we estimate the corresponding VADM to be $(1.82 \pm 0.38) \times 10^{22} \mathrm{~A} \mathrm{~m}^{2}$. These VADMs are $\sim 70 \%$ and $\sim 40 \%$, respectively, of the average Phanerozoic dipole moment from 0.3-300 Ma.

3. The present data and other Precambrian paleointensities are within a range of $\sim 0.5-1.5$ 
times the Phanerozoic mean, with the exception of two anomalously high results.

4. Three sets of paleofield values as a function of paleolatitude (including the Cordova data) from fairly narrow time windows support a dipole configuration for the Earth's magnetic field around 2500-2700 Ma, 1085-1110 Ma, and 850-1000 Ma.

\section{Acknowledgements}

We thank Ken Buchan, Peter Selkin, John Shaw and an anonymous referee for helpful reviews. Mike Jackson of the Institute of Rock Magnetism (IRM) helped with the Kappabridge measurements. The Keck Foundation, the Earth Sciences Division of the National Science Foundation, and the University of Minnesota provide funding for the IRM. This research has been supported by the Natural Sciences and Engineering Research Council of Canada through Grant A7709 to D.J.D.[RV]

\section{References}

[1] E. Thellier, O. Thellier, Sur l'intensité du champ magnétique terrestre dans le passé historique et géologique, Ann. Geophys. 15 (1959) 285-376.

[2] Y. Yu, D.J. Dunlop, Paleointensity determination on the late Precambrian Tudor Gabbro, southern Ontario, J. Geophys. Res. 106 (2001) 26331-26343.

[3] R.M. Easton, The Grenville Province and the Proterozoic history of central and southern Ontario, in: P.C. Thurston, H.R. Williams, R.H. Sutcliffe, G.M. Stott (Eds.), Geology of Ontario, Ontario Geol. Surv. 4 (1992) 715904.

[4] L.T. Silver, S.B. Lumbers, Geochronologic studies on the Bancroft-Madoc area of the Grenville Province, Ontario, Canada, Geol. Soc. Am. Spec. Pap. 87 (1966) 156.

[5] D.W. Davis, J.R. Bartlett, Geochronology of the Belmont metavolcanic complex and implications for crustal development in the Central Metasedimentary Belt, Grenville Province, Can. J. Earth Sci. 25 (1988) 1751-1759.

[6] K.L. Buchan, D.J. Dunlop, Paleomagnetism of the Haliburton intrusions: superimposed magnetizations, metamorphism and tectonics in the late Precambrian, J. Geophys. Res. 81 (1976) 2951-2967.

[7] M.O. McWilliams, D.J. Dunlop, Grenvillian paleomagnetism and tectonics, Can. J. Earth Sci. 15 (1978) 687-695.

[8] V. Costanzo-Alvarez, D.J. Dunlop, A regional paleomag- netic study of lithotectonic domains in the Central Gneiss Belt, Grenville Province, Ontario, Earth Planet. Sci. Lett. 157 (1998) 89-103.

[9] A.B. Weil, R. Van der Voo, C. McNiocaill, J.G. Meert, The Proterozoic supercontinent Rodinia: paleomagnetically derived reconstructions for 1100 to $800 \mathrm{Ma}$, Earth Planet. Sci. Lett. 158 (1998) 13-24.

[10] K.L. Buchan, Magnetic overprinting in the Thanet gabbro complex, Ontario, Can. J. Earth Sci. 15 (1978) 1407 1421.

[11] G.W. Berger, D. York, D.J. Dunlop, Calibration of Grenvillian paleopoles by ${ }^{40} \mathrm{Ar} /{ }^{39} \mathrm{Ar}$ dating, Nature 277 (1979) 46-48.

[12] R.D. Dallmeyer, J.F. Sutter, Acquisition chronology of remanent magnetization along the 'Grenville polar path': Evidence from ${ }^{40} \mathrm{Ar} /{ }^{39} \mathrm{Ar}$ ages of hornblende and biotite from the Whitestone diorite, Ontario, J. Geophys. Res. 85 (1980) 3177-3186.

[13] G.W. Berger, D. York, ${ }^{40} \mathrm{Ar} /{ }^{39} \mathrm{Ar}$ dating of the Thanet gabbro, Ontario: Looking through the Grenvillian metamorphic veil and implications for paleomagnetism, Can. J. Earth Sci. 18 (1981) 266-273.

[14] M.A. Cosca, J.F. Sutter, E.J. Essene, Cooling and inferred uplift/erosion history of the Grenville Orogen, Ontario: Constraints from ${ }^{40} \mathrm{Ar} /{ }^{39} \mathrm{Ar}$ thermochronology, Tectonics 10 (1991) 10959-10977.

[15] M.A. Cosca, E.J. Essene, M.J. Kunk, J.F. Sutter, Differential unroofing within the central metasedimentary belt of the Grenville orogen: constraints from ${ }^{40} \mathrm{Ar} /{ }^{39} \mathrm{Ar}$ thermochronology, Contrib. Miner. Petrol. 110 (1992) 211225.

[16] A.C. Warnock, K.P. Kodama, P.K. Zeitler, Using thermochronometry and low-temperature demagnetization to accurately date Precambrian paleomagnetic poles, J. Geophys. Res. 105 (2000) 19435-19454.

[17] D.J. Dunlop, J.M. Stirling, Post-tectonic magnetizations from the Cordova Gabbro, Ontario and Paleozoic reactivation in the Grenville Province, Geophys. J. R. Astr. Soc. 81 (1985) 521-550.

[18] M. Lopez-Martinez, D. York, Further thermochronometric unravelling of the age and paleomagnetic record of the southwest Grenville Province, Can. J. Earth Sci. 20 (1983) 953-960.

[19] K. Mezger, E.J. Essene, B.A. van der Pluijm, A.N. Halliday, U-Pb geochronology of the Grenville orogen of Ontario and New York: constraints on ancient crustal tectonics, Contrib. Miner. Petrol. 114 (1993) 13-26.

[20] L.M. Annovitz, E.J. Essene, Thermobarometry and pressure-temperature paths in the Grenville Province of Ontario, J. Petrol. 31 (1990) 197-241.

[21] S.R. Dunn, J.W. Valley, Calcite-graphite isotope thermometry: a test for polymetamorphism in marble, Tudor gabbro aureole, Ontario, Canada, J. Metamorph. Geol. 10 (1992) 487-501.

[22] S.R. Dunn, J.W. Valley, Polymetamorphic fluid-rock interaction of the Tudor gabbro and adjacent marble, Ontario, Am. J. Sci. 296 (1996) 244-295. 
[23] G. Pullaiah, E. Irving, K.L. Buchan, D.J. Dunlop, Magnetization changes caused by burial and uplift, Earth Planet. Sci. Lett. 28 (1975) 133-143.

[24] E. McClelland-Brown, Discrimination of TRM and CRM by blocking-temperature spectrum analysis, Phys. Earth Planet. Inter. 30 (1982) 405-414.

[25] D. Dunlop, Ö. Özdemir, Rock Magnetism: Fundamentals and Frontiers, Cambridge University Press, New York, 1997, $573 \mathrm{pp}$.

[26] R. Day, M. Fuller, V.A. Schmidt, Hysteresis properties of titanomagnetites: Grain-size and compositional dependence, Phys. Earth Planet. Inter. 13 (1977) 260-267.

[27] P.R. Renne, G.R. Scott, J.M.G. Glen, J.M. Feinberg, Oriented inclusions of single domain magnetite in clinopyroxene: source of stable remanent magnetization in gabbros of the Messum complex, Namibia, Geochem. Geophys. Geosys. (2002), in press.

[28] T. Nagata, Y. Arai, K. Momose, Secular variation of the geomagnetic total force during the last 5000 years, J. Geophys. Res. 68 (1963) 5277-5281.

[29] R.S. Coe, Paleointensities of the Earth's magnetic field determined from Tertiary and Quaternary rocks, J. Geophys. Res. 72 (1967) 3247-3262.

[30] P.A. Selkin, J.S. Gee, L. Tauxe, W.P. Meurer, A. Newell, The effect of remanence anisotropy on paleointensity estimates: A case study from the Archean Stillwater Complex, Earth Planet. Sci. Lett. 183 (2000) 403-416.

[31] M.W. McElhinny, W.E. Senanayake, Variations in the geomagnetic dipole. 1. The past 50,000 years, J. Geomagn. Geoelectr. 34 (1982) 39-51.

[32] P.A. Selkin, L. Tauxe, Long-term variations in paleointensity, Phil. Trans. R. Soc. Lond. A 358 (2000) 10651088.

[33] M.T. Juárez, L. Tauxe, J.S. Gee, T. Pick, The intensity of the Earth's magnetic field over the past 160 million years, Nature 394 (1998) 878-881.

[34] L.J. Pesonen, H.C. Halls, Geomagnetic field intensity and reversal asymmetry in late Precambrian Keweenawan rocks, Geophys. J. R. Astr. Soc. 73 (1983) 241-270.

[35] K.L. Buchan, J.K. Mortensen, K.D. Card, Correlation of northeast trending Early Proterozoic dyke swarms of the southern Superior Province based on integrated paleomagnetic and U-Pb dating studies, Can. J. Earth Sci. 30 (1993) 1286-1296.

[36] C.J. Hale, Paleomagnetic data suggest link between the Archean-Proterozoic boundary and inner-core nucleation, Nature 329 (1987) 233-237.

[37] I. Sumita, T. Hatakeyama, A. Yoshihara, Y. Hamano,
Paleomagnetism of late Archean rocks of Hamersley basin, Western Australia and the paleointensity at early Proterozoic, Phys. Earth Planet. Inter. 128 (2001) 223241.

[38] E.J. Schwarz, D.T.A. Symons, Paleomagnetic field intensity during cooling of the Sudbury irruptive 1700 million years ago, J. Geophys. Res. 75 (1970) 6631-6640.

[39] J.A. Tarduno, R.D. Cottrell, A.V. Smirnov, High geomagnetic intensity during the mid-Cretaceous from Thellier analyses of single plagioclase crystals, Science 291 (2001) 1779-1783.

[40] C.J. Hale, Evidence of the Archean geomagnetic field, Ph.D. thesis, University of Toronto, 1985, $188 \mathrm{pp}$.

[41] H.C. Palmer, D.W. Davis, Paleomagnetism and U-Pb geochronology of volcanic rocks from Michipicoten Island, Lake Superior, Canada: Precise calibration of the Keweenawan polar wander track, Precamb. Res. 37 (1987) 157-171.

[42] D.J. Dunlop, Ö. Özdemir, Beyond Néel's theories: Thermal demagnetization of narrow-band partial thermoremanent magnetizations, Phys. Earth Planet. Inter. 126 (2001) 43-58.

[43] E. McClelland, J.C. Briden, An improved methodology for Thellier-type paleointensity determination in igneous rocks and its usefulness for verifying primary thermoremanence, J. Geophys. Res. 101 (1996) 21995-22013.

[44] A. Yoshihara, Y. Hamano, Intensity of the Earth's magnetic field in late Archean obtained from diabase dikes of the Slave Province, Canada, Phys. Earth Planet. Inter. 117 (2000) 295-307.

[45] R.S. Coe, C.S. Grommé, M.A. Mankinen, Geomagnetic paleointensities from radiocarbon-dated lava flows on Hawaii and the question of the Pacific nondipole low, J. Geophys. Res. 83 (1978) 1740-1756.

[46] Y. Yu, D.J. Dunlop, L. Pavlish, M. Cooper, Archeomagnetism of Ontario potsherds from the last 2000 years, J. Geophys. Res. 105 (2000) 19419-19433.

[47] A.V. Smirnov, J.A. Tarduno, Archean paleointensity as recorded in North Karelia, Russia (abstract), EOS 81-48 (2000) F365.

[48] C.J. Hale, D.J. Dunlop, Evidence for an early Archean geomagnetic field: A paleomagnetic study of the Komati formation, Barberton belt, South Africa, Geophys. Res. Lett. 11 (1984) 97-100.

[49] C. Morimoto, Y. Otofuji, M. Miki, H. Tanaka, T. Itaya, Preliminary paleomagnetic results of an Archean dolerite dyke of west Greenland: Geomagnetic field intensity at $2.8 \mathrm{Ga}$, Geophys. J. Int. 128 (1997) 585-593. 